\title{
Tolerance by transplantation: how much is enough, how much is too much?
}

Commentary

See related article

this issue, pages 281-290

\author{
Jeffrey L. Platt
}

Transplantation Biology, Departments of Surgery, Immunology, and Pediatrics, Mayo Clinic, Rochester, Minnesota 55905, USA

Address correspondence to: Jeffrey L. Platt, Transplantation Biology, 2-65 Medical Sciences Building, Mayo Clinic, 200 First Street Southwest, Rochester, Minnesota 55905, USA. Phone: (507) 538-0313;

Fax: (507) 284-4957; E-mail: platt.jeffrey@mayo.edu.

In 1900, Ehrlich and Morgenroth observed that the infusion of foreign hematopoietic cells into goats elicited a potent immune response, whereas the infusion of autologous cells did not. They speculated that "the organism possesses certain contrivances by means of which the immunity reaction, so easily produced by all kinds of cells, is prevented from working against the organism's own elements" (1). These contrivances, known collectively as immunological tolerance, are now defined as the absence of an immune response against a specific antigen or cell after a sufficient immune stimulus is given. The tolerant individual should be fully able to mount a response to all other antigens.

The idea that specific immune unresponsiveness might reflect an acquired biological condition was surmised by Owen in 1945 (2). Owen observed that dizygotic twins of cattle have hematopoietic stem cells of both twins in the circulation, owing presumably to their exchange of hematopoietic stem cells (2), a striking observation given the immunogenicity of hematopoietic precursors by the twin fetuses (3). Billingham et al. deliberately induced hematopoietic chimerism in fetal and newborn animals, thereby demonstrating that tolerance induced by chimerism allows the permanent engraftment of skin from the hematopoietic cell donor (4). Why would foreign hematopoietic cells in Ehrlich's goats give rise to immunity, while foreign hematopoietic cells in Owen's cattle give rise to tolerance? The simplest answer is that the fetal immune system is poised for the induction of tolerance, whereas the mature immune system is poised for the induction of immunity. This answer is not entirely satisfactory, however, because the fetus can respond immunologically to certain antigens (e.g., transplacental infections give rise to specific IgM antibodies) and because in mature individuals the repertoire of lymphocytes, being continuously regenerated, must be subject to ongoing induction of tolerance under conditions in which immunity might be induced. An alternative view, then, is that foreign hematopoietic cells stimulate tolerance in developing lymphocytes and immunity or immune regulation (deletion, anergy, or suppression) in mature lymphocytes. In mature individuals, it is the balance of tolerance, immunity, and immune regulation that dictates the intensity and duration of the response.

Several investigators have recently reported that the administration of bone marrow cells expressing Gal $\alpha 1$ $3 \mathrm{Gal}$ into lethally irradiated Gal-deficient mice induces tolerance to $\mathrm{Gal}$ (5, 6). Galo1-3Gal is a saccharide expressed by lower mammals but not by humans and higher primates. Species that do not express this sugar have natural anti-Gal $\alpha 1-3 \mathrm{Gal}$ antibodies that are thought to initiate the rejection of vascularized xenografts (7). Given the intensity of humoral responses to Gal $\alpha 1-3 \mathrm{Gal}$, it is postulated that tolerance to this sugar might contribute to the clinical application of xenotransplantation $(8,9)$. In this issue of the JCI, Ohdan et al. report that tolerance to Gal $\alpha 1-3 \mathrm{Gal}$ can be induced by hematopoietic chimerism (10). To investigate tolerance by chimerism, Ohdan infused wild-type murine bone marrow cells expressing Gal $\alpha 1-3 \mathrm{Gal}$ into mice that do not express $\alpha \mathrm{Gal}$ because of targeted disruption of the gene encoding $\alpha 1,3$-galtransferase $(\alpha 1,3 \mathrm{GT})$, the enzyme that catalyzes synthesis of Gal 1 1-3Gal. These mice, like humans, make antibodies against Gal $\alpha 1-3 \mathrm{Gal}$. To allow engraftment of foreign bone marrow cells, the $\alpha 1,3 \mathrm{GT}$ mice were treated with a sublethal dosage of whole-body irradiation and with anti- $\mathrm{T}$ cell antibodies. The treated mice accepted the bone marrow grafts, had a notable reduction of anti-Gal 1 1-3Gal antibodies, and did not reject subsequently implanted Gal $\alpha 1-3 \mathrm{Gal}^{+}$hearts. If it is not the first report on the induction of tolerance to Gal by hematopoietic chimerism (5, 6), why should Ohdan's work warrant attention and commentary? The answer is that this report begins to explore what may be more important questions: how much tolerance is enough, and how much is too much.

\begin{tabular}{|c|} 
Can chimerism control \\
anti-Galo1-3Gal \\
antibodies to a sufficient \\
extent to allow \\
transplantation to \\
proceed? The study \\
by Obdan et al suggests \\
it can.
\end{tabular}

How much tolerance is enough?

Whenever an approach to immunological tolerance is described in a mouse system, it is prudent to ask whether that approach would work in humans. Achieving tolerance by chimerism would probably be more difficult in humans than in mice. One significant hurdle is the engraftment of xenogeneic bone marrow cells, which is hindered by incompatibility of growth factors between species and by immune-mediated resistance. These problems could be bypassed by using human cells made to express Galo1-3Gal (6), although the chimeric individual would not be made tolerant to other porcine antigens. Another hurdle is eradicating anti-Gal B cells in mature humans, who, compared with $\alpha 1,3 \mathrm{GT}$ mice, have high levels of anti-Gal $\alpha 1-3 \mathrm{Gal}$ antibodies. Human subjects who have 
undergone bone marrow ablation and transplantation with $\mathrm{ABO}$-incompatible bone marrow have been found to make anti-blood group A and B antibodies $(11,12)$. Furthermore, anastomosis of Gal+ organs with human and nonhuman primates would deliver a potent stimulus for the production of anti-Gal $\alpha 1-3 \mathrm{Gal}$ antibodies by remaining anti-Gal B cells (13). The question, then, is whether chimerism can control anti-Gal $\alpha 1-3$ Gal antibodies to a sufficient extent to allow transplantation to proceed. Happily, Ohdan's study suggests that hematopoietic chimerism induces enough tolerance to allow transplantation across the Gal barrier.

\section{How much tolerance is too much?}

Another question, then, must be whether whole-body irradiation and other measures used to induce chimerism in mice would give rise to unacceptable complications in humans. The treatment of adult patients with irradiation and other therapies that deplete lymphocytes might well create an immunological void to be filled only incompletely by newly maturing lymphocytes. Mackall et al. recently showed that following chemotherapy, patients over the age of 18 years have a notably limited abil- ity to regenerate $\mathrm{CD}^{+} \mathrm{T}$ cells (14). The same limitation has been observed following bone marrow transplantation (15). There is also the possibility that the induction of tolerance to Gal $\alpha 1-3 \mathrm{Gal}$ will be accompanied by tolerance to organisms or tumor cells resident in the treated individual. Thus, the clinical application of chimerism may require a compromise: that some fraction of the mature immune response be left intact, including some anti-Gal B cells. Can an organ graft survive and function in the face of ongoing production of anti-donor antibodies? Fortunately, the production of low levels of anti-donor antibodies need not lead inexorably to the demise of an organ graft, as ABO-incompatible kidney grafts in humans and experimental xenografts in baboons (S. Lin, unpublished observations) can acquire resistance to injury by anticarbohydrate antibodies, a condition we have called accommodation (16).

1. Ehrlich, P., and Morgenroth, J. 1957. On hamolysins. Fifth communication. In The collect ed papers of Paul Ehrlich. Volume 2. F. Himmelweit, editor. Pergamon. London, United Kingdom. 246-255.

2. Owen, R. 1945. Immunogenetic consequences of vascular anastomoses between bovine twins. Science. 102:400-401.

3. Billingham, R.E., Brent, L., and Medawar, P.B. 1955. Acquired tolerance of skin homografts.
Ann. NY Acad. Sci. 59:409-416.

4. Billingham, R.E., Brent, L., and Medawar, P.B 1953. Actively acquired tolerance of foreign cells. Nature. 172:603

5. Yang, Y.-G., et al. 1998. Tolerization of antiGal $\alpha 1-3 \mathrm{Gal}$ natural antibody-forming B cells by induction of mixed chimerism. J. Exp. Med. 187:1335-1342.

6. Bracy, J.L., Sachs, D.H., and Iacomini, J. 1998. Inhibition of xenoreactive natural antibody production by retroviral gene therapy. Science. 281:1845-1847.

7. Galili, U. 1993. Interaction of the natural antiGal antibody with $\alpha$-galactosyl epitopes: a major obstacle for xenotransplantation in humans. Immunol. Today. 14:480-482.

8. Sachs, D.H., and Sablinski, T. 1995. Tolerance across discordant xenogeneic barriers. Xenotransplantation. 2:234-239.

9. Platt, J.L. 1998. New directions for organ transplantation. Nature. 392(Suppl.):11-17.

10. Ohdan, H., Yang, Y.-G., Shimizu, A., Swenson, K.G., and Sykes, M. 1999. Mixed bone marrow chimerism induced without lethal conditioning prevents $\mathrm{T}$ cell- and anti-Gal $\alpha 1,3$ Gal-mediated heart graft rejection. J. Clin. Invest. 104:281-290

11. Buckner, C.D., et al. 1978. ABO-incompatible marrow transplants. Transplantation. 26:233-238.

12. Gmür, J.P., et al. 1990. Pure red cell aplasia of long duration complicating major $\mathrm{ABO}$-incompatible bone marrow transplantation. Blood. 75:290-295.

13. Cotterell, A.H., Collins, B.H., Parker, W., Harland, R.C., and Platt, J.L. 1995. The humoral immune response in humans following cross-perfusion of porcine organs. Transplantation. 60:861-868.

14. Mackall, C.L., et al. 1995. Age, thymopoiesis, and CD4+ T-lymphocyte regeneration after intensive chemotherapy. N. Engl. J. Med. 332:143-149.

15. Forman, S.J., et al. 1982. Pattern of T-cell reconstitution following allogeneic bone marrow transplantation for acute hematological malignancy. Transplantation. 34:96-98.

16. Platt, J.L., et al. 1990. Transplantation of discordant xenografts: a review of progress. Immunol. Today. 11:450-456. 